\title{
Environmental Health Information Partnership (EnHIP): Strengthening the Capacity of Minority Serving Institutions
}

\author{
Gale A. DUTCHER M.S. M.L.S. ${ }^{\text {a1 }}$ and John C. SCOTT M.A. ${ }^{b}$ \\ ${ }^{\text {a } U . S . ~ N a t i o n a l ~ L i b r a r y ~ o f ~ M e d i c i n e ~(r e t i r e d) ~}$ \\ ${ }^{\mathrm{b}}$ Center for Public Service Communications, U.S.A.
}

\begin{abstract}
The U.S. National Library of Medicine's (NLM) Environmental Health Information Partnership (EnHIP) collaborates with Historically Black Colleges and Universities (HBCUs) and other minority-serving academic institutions to enhance their capacity to reduce health disparities through the access, use, and delivery of environmental health information on their campuses and in their communities. The partnership began in 1991 as the Toxicology Information Outreach Panel (TIOP) pilot project, and through successive iterations it is NLM's longest running outreach activity. EnHIP's continued relevance today as an information outreach and training program testifies to the prescience of NLM director, Donald A.B. Lindberg M.D's initial support for the program. Dr. Lindberg's seeing to its continued success to benefit participating institutions and help achieve the societal goals of environmental justice serve as well to benefit NLM by increasing its visibility, and use of its resources in the classroom, for research, and in community outreach. NLM envisions an expanding role for EnHIP in advancing health equity as the impact of environmental exposure, climate change, and increasing zoonotic diseases disproportionately impact their communities
\end{abstract}

Keywords. U.S. National Library of Medicine, Donald A.B. Lindberg M.D., Environmental Health Information Partnership, Historical Black Colleges and Universities, Health Disparities, Environmental Justice, Outreach.

In Memory of Melvin L. Spann Ph.D., 1941-2019.

Director, Specialized Information Services, U.S. National Library of Medicine

\section{Introduction}

The U.S. National Library of Medicine's (NLM) Environmental Health Information Partnership (EnHIP) is a collaboration between NLM and Historically Black Colleges and Universities (HBCUs), a Predominately Black Institution (PBI), Hispanic-Serving Institutions (HSIs), Tribal Colleges and Universities (TCUs), an Alaska Native-Serving Institution, and a community college. EnHIP evolved from the Toxicology Information Outreach Panel (TIOP) which was established in 1991 as a pilot project in response to the pressing issue of toxic waste and the exposure of toxic chemicals in minority communities. Its mission is to enhance the capacity of minority-serving academic

\footnotetext{
${ }^{1}$ Corresponding author: Gale A. Dutcher, E-mail: gad695@yahoo.com
} 
institutions to reduce health disparities through the access, use, and delivery of environmental health information on their campuses and in their communities.

EnHIP's beginning can be traced to 1966 at a time of increased concern over the potential effects of environmental chemicals on peoples' health. The U.S. President's Science Advisory Committee (PSAC) examined the state of information in the growing science of toxicology and concluded that "there exists an urgent need for a much more coordinated and more complete computer-based file of toxicological information than any currently available and, further, that access to this file must be more generally available to all those legitimately needing such information" [1]. That recommendation led to the establishment of the Toxicology Information Program at the U.S. National Library of Medicine (NLM).

Further, in 1988, a U.S. Senate Appropriations Committee amendment to NLM's funding authorization mandated that NLM's mission be expanded "...to reach all American health professionals, wherever located, so that they will be able to take advantage of the library's information services." In response to this directive, a 1989 NLM planning panel chaired by Michael E. DeBakey M.D. developed recommendations to guide the library's development of a Library-wide outreach program to improve access to NLM's information resources and take advantage of newly emerging information and computer technologies [2]. The Toxicology Information Program was a model for the extensive outreach initiatives that would follow. In subsequent iterations, it would become NLM's longest-standing outreach program.

In 1991, Charles Walker Ph.D. stepped down from his position as Chancellor of the University of Arkansas at Pine Bluff, an historically Black University. NLM director, Donald A.B. Lindberg M.D. recognized this as an opportunity and invited Dr. Walker to lead NLM's newly created Office of Outreach Development within the Office of Health Information Programs Development. Dr. Walker was keenly interested in connecting underserved health professionals - many of whom practiced in rural and inner-city minority communities - to the library's electronic medical information resources. His initial focus was on the Lower Mississippi Delta region, one of the poorest areas of the nation.

Dr. Walker soon collaborated with Melvin Spann Ph.D., then Chief of the Biomedical Information Services Branch, Division of Specialized Information Services, to create a new outreach project centered around the Toxicology Information Program and a group of Historically Black Colleges and Universities (HBCUs). In just a year's time, NLM lost Dr. Walker who's untimely passing greatly saddened all with whom he worked [3].

Drs. Spann and Walker championed the need for the training of minority health professionals in the use of NLM's electronic information resources. With Dr. Lindberg's strong encouragement and advice, a pilot project was launched, and a select group of senior advisers and stakeholders was convened as the first meeting of the Toxicology Information Outreach Panel (TIOP) in August 1991.

\section{Toxicology Information Outreach Panel (TIOP) Aligns with HBCUs}

Drs. Lindberg, Spann and Walker recognized that NLM could play an important role in improving the health of minority communities most affected by exposure to toxic chemicals through improving access to the library's information resources by health professionals serving those communities. An obvious way to do this was to work with 
the Historically Black Colleges and Universities (HBCUs) who graduate health professionals and other individuals taking leadership positions in these communities.

HBCUs were created by the enactment of the Second Morrill Act in 1890. The Act required states with racially segregated public higher education systems to provide a land-grant institution for black students whenever a land-grant institution was established and restricted to white students. The Higher Education Act of 1965, as amended, defines an HBCU as: ".... any historically black college or university that was established prior to 1964 , whose principal mission was, and is, the education of black Americans, and that is accredited by a nationally recognized accrediting agency."

Why are HBCUs important for this effort? According to a 1991 document by the U.S. Department of Education's Office for Civil Rights, the two oldest HBCU medical schools, Meharry Medical College and Howard University, have combined to produce over $80 \%$ of African American doctors and dentists practicing in the United States at that time [4]. It would not be until 1966, shortly after the Civil Rights Act, that African Americans were admitted into all U.S. medical schools. HBCUs have been successful in premedical education as well [5].

When the Toxicology Information Outreach Panel (TIOP) started as a pilot project in 1991, it included senior representatives from eight HBCUs and a minority-serving educational institution. (Charles Drew University of Medicine and Science is technically not an HBCU since it was started in 1966.)

- Charles R. Drew University of Medicine and Science, Los Angeles, CA

- Florida A\&M University, Tallahassee, FL

- Howard University, Washington, DC

- Meharry Medical College, Nashville, TN

- Morehouse School of Medicine, Atlanta, GA

- Texas Southern University, Houston, TX

- Tuskegee University, Tuskegee, AL

- University of Arkansas at Pine Bluff, Pine Bluff, AR

- Xavier University, New Orleans, LA

These institutions included four medical schools, a veterinary school, and nursing and graduate programs. Each institution on the Panel was represented by a Dean, Department Chair, or other senior faculty member. Dr. Bailus Walker, then at the University of Oklahoma, was appointed chair of the panel by Dr. Lindberg. Dr. Bailus Walker was a well-known scientist with research interests in lead toxicity and environmental carcinogenesis. In addition to the HBCUs, participants included representation from other government agencies including the U.S. Agency for Toxic Substances and Disease Registry (ATSDR), U.S. Environmental Protection Agency, U.S. National Institute of Occupational Safety and Health, U.S. National Science Foundation, and several consultants.

\subsection{Training}

The main charge to TIOP was to develop strategies to strengthen the capacity of HBCUs to use the toxicological, environmental, and occupational information resources developed by NLM. Each participating institution received a customized personal computer (PC) workstation along with specially designed tutorial programs, and free 
access to NLM's databases. It is worth noting that in 1991, PCs were not ubiquitous as they are now and were quite expensive. Indeed, a few of the schools reported that these workstations might have been the first ones in their departments on campus. NLM also provided extensive and repeated training in the use of its online databases. Between the in-person training and the customized tutorials, this was intended to be a train-the-trainer program where NLM would provide training to faculty who would then incorporate this into their courses.

This program was seen as so worthwhile that both ATSDR and EPA provided funding to NLM to expand the training program to include over 80 additional HBCUs not part of TIOP [6]. Dr. Charles Walker was instrumental in gaining support from ATSDR.

The HBCU participants at this first meeting of TIOP made many points and recommendations that would become the basis for the project as it continued after the one-year pilot. The most important item in the early stages of this project was the ongoing training provided by NLM and staff from the Oak Ridge Institute for Science and Education (ORISE) located at the U.S. Department of Energy's facility in Tennessee. It was primarily the ORISE staff who, over time, traveled to each of the HBUCs to conduct the actual training sessions. Only by bringing the HBCUs into an understanding of the utility of the NLM online databases was it possible for faculty to begin to incorporate them into their classes and their research. It is important to remember that this was at a time when online searching was not user-friendly and personal computers were expensive and not in widespread use. The panel was also prescient in their recommendation that NLM implement a funding program for these institutions and create an electronic means for networking among the representatives. These activities came much later.

NLM found that this pilot project was sufficiently successful that is should be continued, and the training expanded to additional HBCUs. The panel met at least annually at NLM with Dr. Lindberg in attendance at each meeting. The NLM director's presence and active participation made it clear to the panel members that NLM viewed this as a significant undertaking.

\subsection{Growth and Development}

In 1997 the decision was made to add representation from Hampton University, Hampton, VA, to TIOP. Hampton has a strong nursing program as well as experience working with their community through the Environmental Justice Information Center. Several years later, in 2001, the TIOP expanded to include institutions serving other minorities, since these populations also experience disparities in health and toxic environmental exposures. The Oglala Lakota Tribal College and the University of Puerto Rico Medical Sciences Campus were added to TIOP. Oglala Lakota College (OLC) was one of the first tribally controlled colleges in the United States. The concept of a tribally controlled college is that it be sanctioned by an Indian tribe, be governed by an Indian tribe, its governing body be made up of tribal members, and that it meets the needs of reservation people in their pursuit of higher education. The OLC nursing program supplies nursing health care providers to the rural and Pine Ridge/Rosebud Indian reservation areas of the northern plains. 


\subsection{Assessment}

2001 marked the tenth year of this pilot project. It was an appropriate time to review of the program and to provide a basis for whether and how to continue. John Scott, director of the Center for Public Service Communications and an NLM consultant, was commissioned to carry out the review [7].

During individual interviews, the panel members offered a long list of the different ways TIOP had an impact on their institutions including supporting the creation of various graduate programs and libraries and promoting the implementation of Internet access for the campus. Several of the TIOP representatives reported that by providing connectivity and computers, this project opened up NLM's databases directly to the faculty and students. Prior access was either too expensive or only available through the librarian, which was a good service but did limit access and exploration.

The consensus was that TIOP did fulfill its goal to increase awareness and use of NLM's databases at the participating institutions. But the TIOP representatives felt that they could do more to help NLM as well as benefit their own institutions. They recommended modifying the program objectives to include health disparities, to broaden representation with additional minority serving institutions, and to increase the interaction between the institutions and NLM. A new mission statement was proposed at the 2003 meeting: "The mission of the Environmental Health Information Outreach Panel is to enhance the capacity of minority-serving academic institutions to reduce health disparities through the access, use, and delivery of environmental health information on their campuses and in their communities."

In response to the assessment and with the support of Dr. Lindberg, NLM and TIOP made several additional changes to the program. Clearly, this was no longer a pilot project; it was an ongoing program of the National Library of Medicine.

Regarding staffing, Gale Dutcher assisted Dr. Spann with TIOP, and when he retired in 1999, she assumed responsibility for direction and oversight of TIOP/EnHIP in her role as head of the SIS's Office of Outreach and Special Populations. She was assisted by Cynthia Gaines, the EnHIP project officer, who managed the process of organizing the meetings. John Scott, an outside consultant, advised NLM staff and Panel leadership. Scott brought considerable expertise in minority health and community outreach to EnHIP, as well as to other important outreach initiatives undertaken NLM-wide.

\section{Environmental Health Information Outreach Program (EnHIOP)}

In 2004, the Panel evolved from TIOP to Environmental Health Information Outreach Program (EnHIOP) to reflect what was now a wider outreach program as more schools were added to the program in order to reflect more diversity in participating institutions [8]. The group established some long-term goals to guide the program into the future. These goals included further institutionalizing NLM resources, strengthening institutional partnerships with libraries and other information centers, boosting and developing community-based and faith-based organizations to extend health-related outreach to communities surrounding participating institutions, and increasing participation within the schools through professional meetings, presentations, and panel discussions. 
Dr. Lindberg commended the group for its perseverance and sense of mission that had made it possible for the program to last for 10 years, stating that this was a remarkable accomplishment that demonstrated a commitment to paying attention to underserved populations. He also offered several recommendations to the panel including budgeting sufficient time to know each other and work together; understanding the history and laws of the participating institutions and their current needs; consider extending the EnHIOP meetings beyond one day to allow presentations on new topics and by external experts; sharing best practices - with each other and with NIH; identifying high priority opportunities and writing proposals to explore them. He reminded them that although NLM itself can act only upon those things the institution is entitled to act upon, it can also be a conduit to other agencies and other parts of the U.S. National Institutes of Health $(\mathrm{NIH})$ that are also committed to these goals. He emphasized the importance of toxicology and environmental health to NIH and its relationship to other topics of interest.

EnHIOP and NLM staff determined that two ways to respond to Dr. Lindberg's comments were to increase the number of meetings to two per year and hold one of those meetings at one of the institutions participating in EnHIOP. This would allow the participants to gain a better understanding of the various institutions and foster more participation by faculty at those institutions and their local communities. Further, the group determined that it would be important to tie the work of EnHIOP to NLM's Long Range Plan.

\section{Environmental Health Information Partnership (EnHIP)}

As more institutions joined the program, its name was changed in 2009 to Environmental Health Information Partnership (EnHIP) which defined the program's true status as a partnership between NLM and leading educational institutions. The Partnership now reflects a broader focus on the multicultural dimensions of environmental health, environmental health sciences, and health disparities.

\section{Moving from Campus to Community}

Based on Dr. Lindberg's advice and internal discussions, NLM committed to funding small outreach projects for EnHIOP/EnHIP member institutions. HBCUs and other minority serving educational institutions are of critical importance to their surrounding communities. HBCUs have traditionally played a key role in the education of African Americans, and tribal colleges and Hispanic serving educational institutions play parallel roles for their respective constituency groups. Graduates of these institutions often play leadership roles in their communities. Further, the institutions themselves, students, and faculty are involved in a wide variety of local community outreach working to better their geographic areas. As NLM began to play a greater role in providing consumer health information, it was clear that the EnHIOP institutions could play a significant role in developing diverse model community outreach programs. Therefore, starting in 2005, NLM made small awards of $\$ 5,000$ to EnHIOP participating institutions for local community health information outreach projects. The most recent awards were made in 2018 . 


\section{Review of EnHIP}

To validate the impact and continued relevance of EnHIP and to help guide the Partnership in the future, NLM, with assistance from Oak Ridge Associated Universities, conducted a needs assessment in 2015-2016. The review found that the EnHIP representatives used NLM resources and their participation in the Partnership to improve environmental courses at their institutions and they included this information and their involvement with NLM in grant submissions. They shared their information with faculty and staff at their institutions and presented it at lectures and outreach activities. Representatives also mentioned the benefits of networking and collaboration among member institutions and enhancing their institutions' capacity to conduct research and publish on health issues for minority and underserved populations. While it was clear that the institutions benefited from their participation in EnHIP, NLM also benefited by its increased visibility at these minority serving institutions and increased use of its resources in the classroom, for research, and in community outreach projects.

\section{Continuing Importance of the Environmental Health Information Partnership}

TIOP was started because of the recognition of the profound impact of environmental exposure to toxic substances on minority communities. A number of protests and publications in the 1980's brought the issue of environmental racism to the public's awareness. "This is environmental racism: How a protest in a North Carolina farming town sparked a national movement", by Darryl Fears and Brady Dennis writing for the Washington Post on April 6, 2021, clearly shows how one of the most significant incidents started the environmental justice movement [9]. Similarly, a seminal 1987 study by the United Church of Christ, "A National Report on the Racial and SocioEconomic Characteristics of Communities with Hazardous Waste Sites" documented the relationship between the placement of toxic waste dumps and race and economic conditions [10]. It clearly shows that race rather than economic level was most important in the siting of toxic waste dumps. Work on toxicology, environmental health and health disparities continues to be quite relevant. It is more than unfortunate the UCC's updated study, “Toxic Wastes and Race at Twenty 1987-2007” suggests there is still a great need for work in this area [11]. This report found that racial disparities in the location of toxic waste facilities were "greater than previously reported People of color comprised most of the population in communities within 1.8 miles of a facility." This certainly testifies to the continued relevance of EnHIP and the importance of the availability of toxicology and environmental health information.

\subsection{A Look to the Future}

NLM is continuing to support and work with EnHIP. In addition to regular meetings, NLM makes awards for community information outreach projects. A virtual meeting was held in 2020 due to COVID-19, the main topic revolved around the global pandemic. The institutions participating in EnHIP are well positioned to engage with their communities to hear their concerns and ensure that they are getting the most up-to-date health and medical information about COVID-19 transmission, treatment, and prevention. It is important that minority communities which are the most seriously impacted by the disease, can access accurate information from trusted sources. EnHIP 
institutions are such trusted sources and can help to combat a lot of the misinformation being shared person to person and by social media. There is an ongoing role for EnHIP, perhaps even an expanding role in advancing health equity as the impact of environmental exposure, climate change, and increasing zoonotic diseases disproportionately impact their communities.

\section{References}

[1] Institute of Medicine. Toxicology and environmental health information resources: the role of the National Library of Medicine. Washington, DC: The National Academies Press; 1997. https://doi.org/ $10.17226 / 5496$.

[2] National Library of Medicine (US). Board of Regents. Improving health professionals' access to information. [Internet] Bethesda, Md.: U.S Dept. of Health and Human Services, National Institutes of Health, 1989 [cited 2021 July 8]. 28p. Available from: https://collections.nlm.nih.gov/ext/kirtasbse/ 8912965/PDF/8912965.pdf

[3] NLM mourns Charles Walker. NIH Record [Internet]. XLIV(13):15. June 23, 1992 [cited 2021 July 8]. Available from: https://nihrecord.nih.gov/sites/recordNIH/files/pdf/1992/NIH-Record-1992-06-23.pdf

[4] Department of Education. Office for Civil Rights. Historically black colleges and universities and higher education desegregation. [Internet]. Washington, DC, March 1991[cited 2021 July 8]. Available from: https://www2.ed.gov/about/offices/list/ocr/docs/hq9511.html

[5] Gasman M, Smith T, Ye C. HBCUs and the production of doctors. AIMS Public Health. 2017. 4(6): 57989. PMID:30155503

[6] Dutcher GA, Spann M, Gaines C. Addressing health disparities and environmental justice: the National Library of Medicine's Environmental Health Information Outreach Program. J Med Libr Assoc. July 2007. 95(3):330-6.

[7] Scott JC. Toxicology Information Outreach Project (TIOP) assessment report. Center for Public Service Communications. [Internet] Arlington, VA, August 2001 [cited 2021 July 8]. Available from: https://www.nlm.nih.gov/oet/partnerships/enhip-reports/august2001TIOPReport.pdf

[8] National Library of Medicine. Environmental Health Information Outreach Program minutes. [Internet] January 14, 2004 [cited 2021 July 8]. Available from: https://www.nlm.nih.gov/oet/partnerships/enhipreports/2004_enhiop_meeting.pdf

[9] Fears D, Brady D. This is environmental racism. Washington Post. [Internet] April 6, 2021 [cited 2021 July 8]. Available from: https:/www.washingtonpost.com/climate-environment/interactive/2021/ environmental-justice-race/?tid=a_classic-iphone\&no_nav=true

[10] United Church of Christ. Commission for Racial Justice. Toxic wastes and race in the United States: A national report on the racial and socio-economic characteristics of communities with hazardous waste sites. [Internet] New York, NY, 1987 [cited 2021 July 8]. Available from: https://www.nrc.gov/docs/ ML1310/ML13109A339.pdf

[11] Bullard RD, Mohal P, Saha R, Wright B. Toxic wastes and race at twenty 1987-2007. A report prepared for the United Church of Christ justice \& witness ministries. [Internet] Cleveland, OH, March 2007 [cited 2021 July 8]. Available from: https://www.ucc.org/wp-content/uploads/2021/03/toxic-wastes-and-raceat-twenty-1987-2007.pdf 